\title{
Nucleotide variants in hepatitis B virus preS region predict the recurrence of hepatocellular carcinoma
}

\author{
Xi Chen ${ }^{1,}{ }^{*}$, Minfeng Zhang ${ }^{2,}$, Nan $\mathrm{Li}^{2}$, Rui Pu${ }^{1}$, Ting Wu ${ }^{1}$, Yibo Ding ${ }^{1}$, Peng Cai ${ }^{1}$, Hongwei Zhang ${ }^{1}$, \\ Jun Zhao², Jianhua Yin ${ }^{1, \&}$, Guangwen Cao ${ }^{1}$ \\ ${ }^{1}$ Department of Epidemiology, Faculty of Navy Medicine, Second Military Medical University, Shanghai, China \\ ${ }^{2}$ Department of Surgery, Eastern Hepatobiliary Surgery Hospital, Second Military Medical University, Shanghai, \\ China \\ *Equal contribution
}

Correspondence to: Jianhua Yin, Guangwen Cao; email: hawkyih163@163.com, https://orcid.org/0000-0003-1047-7059; gcao@smmu.edu.cn

Keywords: hepatitis B virus, viral variant, prediction model, hepatocellular carcinoma, prognosis

Received: March 31, $2021 \quad$ Accepted: September 3, $2021 \quad$ Published: September 17, 2021

Copyright: (C) 2021 Chen et al. This is an open access article distributed under the terms of the Creative Commons Attribution License (CC BY 3.0), which permits unrestricted use, distribution, and reproduction in any medium, provided the original author and source are credited.

\section{ABSTRACT}

Background: Hepatitis B virus (HBV) variants in the preS region have been associated with hepatocellular carcinoma (HCC). However, the effect of the preS variants on HCC prognosis remains largely unknown. We aimed to identify the preS variants that reliably predict postoperative prognosis in HCC.

Methods: RNA-seq data of 203 HCC patients retrieved from public database were screened for the preS variants related to HCC prognosis. The variants in the sera and tumors were then validated in our prospective cohort enrolling 103 HBV-associated HCC patients.

Results: By analyzing prognosis-related gene sets in the RNA-seq data, $12 \mathrm{HBV}$ preS variants were associated with $\mathrm{HCC}$ recurrence. Of those, $\mathrm{G} 40 \mathrm{C}$ and $\mathrm{C} 147 \mathrm{~T}$ in the sera predicted an unfavorable recurrence-free survival in our cohort (hazard ratio $[\mathrm{HR}]=2.18,95 \%$ confidence interval $[\mathrm{Cl}]=1.37-3.47, p=0.001$ for $\mathrm{G} 40 \mathrm{C}$; HR=1.84, 95\% $\mathrm{Cl}=1.15-2.92, p=0.012$ for $\mathrm{C} 147 \mathrm{~T})$. G40C and C147T were significantly associated with microscopic vascular invasion, larger tumor size, and abnormal liver function. Multivariate Cox regression analysis showed that G40C significantly increased the risk of HCC recurrence in patients with postoperative antiviral treatment. The HCC prognosis-prediction model consisting of $\alpha$-fetoprotein and G40C in the sera achieved the best performance (sensitivity $=0.80$, specificity $=0.70$, and area under the curve $=0.79$ ). Functional analysis indicated that these two variants were associated with cell proliferation, chromosome instability, carcinogenesis, metastasis, and anticancer drug resistance.

Conclusions: G40C and C147T are serological biomarkers for HCC prognosis and the prognostic model consisting of serological $\alpha$-fetoprotein and G40C achieved the best performance in predicting postoperative prognosis.

\section{INTRODUCTION}

Hepatocellular carcinoma (HCC) is one of the deadliest malignant diseases. Chronic hepatitis B virus (HBV) infection is the most common cause of HCC worldwide [1]. During HBV-induced carcinogenesis, HBV keeps evolving. Some HBV mutants can promote the development of HCC $[2,3]$. Due to the absence of a proofreading function for HBV polymerase, HBV has a relatively higher mutation rate during virus replication [4]. Mutations, especially mutations in the preS region of the HBV genome, are associated with advanced liver diseases, including HCC [5]. Both preS1 and preS2 deletions can cause unbalanced production of $\mathrm{HBV}$ envelope proteins, with consequent accumulation of the mutated large HBV surface antigen (LHBS) in the endoplasmic reticulum (ER) of hepatocytes, causing ER stress and, ultimately, HCC development [6-8]. A meta- 
analysis including $5563 \mathrm{HBV}$-infected patients has demonstrated that $\mathrm{HBV}$ preS deletion is significantly associated with an increased risk of $\mathrm{HCC}$, with a summary odds ratio of 3.0 [9]. Importantly, HBV preS mutations especially deletions and some HCCassociated preS point mutations are present at least 10 years before the development of HCC [10]. These studies indicate that $\mathrm{HBV}$ preS mutations can predict the development of HCC in HBV-infected subjects.

The recurrence rate of $\mathrm{HCC}$ is high after curative resection. It is important to predict the prognosis of HCC before surgical treatment. However, reliable biomarkers for predicting HCC prognosis are lacking. Previous studies have demonstrated that higher viral load, preS deletion mutations, and higher expression of LHBS with partial pre-S2 deletion in the tumors may significantly predict the postoperative prognosis of HBV-caused HCC (HBV-HCC) cases [11-14]. However, there is no study reporting whether nucleotide variants in the preS region of $\mathrm{HBV}$ genome are prognostic for HCC. In this study, HBV variants in the preS region associated with postoperative prognosis of HBV-HCC were first examined by analyzing RNAseq datasets of HCC tissues. The variants were independently validated in the sera and paired tumor tissues of HBV-HCC patients who received radical hepatectomy in a prospective cohort.

\section{RESULTS}

\section{Screening of prognostic HBV preS variants in RNA- seq data}

We combined the RNA-seq datasets of tumor samples of $203 \mathrm{HBV}-\mathrm{HCC}$ patients from a total of twelve studies. HBV reads could not be detected in 37 of them, while the median depth of HBV was 477.81 (IQR, 71.05-1639.56) in the remaining 166 samples. The variants at the preS region (nt. 2848 to nt. 154) covered by more than 100 reads were extracted by a procedure taking sequencing error into account. The frequencies of those variants without sufficient coverage were considered not available. To estimate the associations between HBV variants and postoperative prognosis of HCC patients, HCC-specific prognosis-related gene sets were retrieved from MsigDB and compiled into an inhouse database, which contained six overall survival (OS)-related and seven recurrence-free survival (RFS)related gene sets (Supplementary Table 1). After adjusting for any potential batch effect, sample-level enrichment scores were calculated for every gene set and correlation tests were performed. It was found that $12 \mathrm{HBV}$ variants were significantly associated with RFS of HCC patients, while none was found to be associated with OS (Supplementary Table 2).

\section{Validation of prognostic HBV preS variants in a prospective cohort}

To validate these variant-prognosis associations predicted by RNA-seq data, 103 HBV-HCC patients were enrolled in our prospective cohort (Table 1). Their sera and tumor tissues were collected and subjected to clone-based Sanger sequencing for HBV preS region. Multiple clones were sequenced for each sample, with a median clone number in the serum sample of 9 (IQR, 710) and in the tumor sample of 7 (IQR, 6-9). To inspect the inter-subject contamination, a heat map was plotted and indicated that there was no between-subject contamination (Supplementary Figure 1). The presence/ absence of the HBV variants was summarized for each sample. Our survival analysis indicated that G40C and $\mathrm{C} 147 \mathrm{~T}$ in the tumors were significantly associated with RFS (Supplementary Table 3).

In the correlation test of RNA-seq, the frequencies of G40C and C147T were all associated with a gene set named "KUROKAWA_LIVER_CANCER_EARLY_ RECURRENCE_UP" consisting of genes upregulated in HCC with early recurrence $(r=0.29$, false discovery rate $(\mathrm{FDR})=0.025$ for $\mathrm{G} 40 \mathrm{C} ; \mathrm{r}=0.24, \mathrm{FDR}=0.082$ for C147T) (Supplementary Table 2). In the survival analysis of our 103 patients, the presence of these two variants in the tumors also predicted unfavorable RFS $(\mathrm{HR}=1.78,95 \% \mathrm{CI}=1.04-3.05, p=0.045$ for $\mathrm{G} 40 \mathrm{C}$; $\mathrm{HR}=1.74,95 \% \mathrm{CI}=1.03-2.95, p=0.039$ for $\mathrm{C} 147 \mathrm{~T}$ ) (Figure 1A and Supplementary Table 3).

\section{Evaluation of the $\mathrm{HBV}$ variants as serological biomarkers for HCC prognosis}

To evaluate if these HBV variants serve as serological biomarkers predicting prognosis of HCC patients, we performed survival analyses using these variants in the sera. The presence of G40C and C147T in the sera both predicted unfavorable RFS $(\mathrm{HR}=2.18,95 \% \mathrm{CI}=1.37$ 3.47, $p=0.001$ for $\mathrm{G} 40 \mathrm{C}$; $\mathrm{HR}=1.84,95 \% \mathrm{CI}=1.15-2.92$, $p=0.012$ for C147T). Kaplan-Meier curves and log-rank tests also confirmed these results (Figure 1B). These two variants are polymorphic sites between the HBV genomes of HBV genotypes B2 and C2 compared to the HBV reference sequences and were highly linked. The wild types at nt. 40 and nt. 147 are $\mathrm{G}$ and $\mathrm{C}$ in genotype $\mathrm{C} 2$, and $\mathrm{C}$ and $\mathrm{T}$ in genotype $\mathrm{B} 2$, respectively. Besides, G40C does not alter amino acid, while C147T results in amino acid change from alanine to valine. By correlation tests, we found that the two variants tended to occur together, and their correlation coefficient was 0.96 in the sera. If the patients with these two variants in the sera were treated as a group, survival analysis and Kaplan-Meier curve could confirm the prediction power of two individual variants $(\mathrm{HR}=2.18,95 \% \mathrm{CI}=1.37$ 
Table 1. Baseline characteristics of patients enrolled in our cohorts ${ }^{\dagger}$.

\begin{tabular}{|c|c|c|}
\hline Variable & Level & Cohort in the study $(n=103)$ \\
\hline Age - yr & & $50.09 \pm 8.71$ \\
\hline \multirow{2}{*}{ Gender } & Male & $93(90.3)$ \\
\hline & Female & $10(9.7)$ \\
\hline \multirow[t]{2}{*}{ BMI $-\mathrm{kg} / \mathrm{m}^{2}$} & & $23.50 \pm 3.75$ \\
\hline & B & $9(8.7)$ \\
\hline \multirow[t]{2}{*}{ HBV genotype (sera) } & $\mathrm{C}$ & $67(65.1)$ \\
\hline & Mixture & $27(26.2)$ \\
\hline \multirow{2}{*}{ Ascites } & No & $89(86.4)$ \\
\hline & Yes & $14(13.6)$ \\
\hline \multirow{2}{*}{ Tumor rupture } & No & $100(97.1)$ \\
\hline & Yes & $3(2.9)$ \\
\hline \multirow{2}{*}{ Portal vein tumor thrombi } & No & $84(81.6)$ \\
\hline & Yes & $19(18.4)$ \\
\hline \multirow{2}{*}{ Tumor number } & Single & $85(82.5)$ \\
\hline & Multiple & $18(17.5)$ \\
\hline \multirow{2}{*}{ Tumor size } & $<3 \mathrm{~cm}$ & $16(15.5)$ \\
\hline & $\geq 3 \mathrm{~cm}$ & $87(84.5)$ \\
\hline \multirow{3}{*}{ Cirrhosis } & No & $7(6.8)$ \\
\hline & Mild Cirrhosis & $71(68.9)$ \\
\hline & Cirrhosis & $25(24.3)$ \\
\hline \multirow{3}{*}{ Tumor capsule } & Complete & $16(15.5)$ \\
\hline & Incomplete & $73(70.9)$ \\
\hline & Absence & $14(13.6)$ \\
\hline \multirow{2}{*}{ Microsatellite } & No & $74(71.8)$ \\
\hline & Yes & $29(28.2)$ \\
\hline \multirow{2}{*}{ Microscopic vascular invasion } & No & $65(63.1)$ \\
\hline & Yes & $38(36.9)$ \\
\hline \multirow{3}{*}{ Tumor differentiation } & I & $14(13.6)$ \\
\hline & II & $7(6.8)$ \\
\hline & III & $82(79.6)$ \\
\hline \multirow{4}{*}{ BCLC staging } & 0 & $0(0.0)$ \\
\hline & A & $36(35.0)$ \\
\hline & B & $48(46.6)$ \\
\hline & $\mathrm{C}$ & $19(18.4)$ \\
\hline \multirow{2}{*}{$\begin{array}{l}\text { Postoperative antiviral } \\
\text { treatment }\end{array}$} & No & $58(56.3)$ \\
\hline & Yes & $45(43.7)$ \\
\hline \multirow{2}{*}{$\mathrm{HBeAg}$} & Negative & $83(70.6)$ \\
\hline & Positive & $20(19.4)$ \\
\hline \multirow{3}{*}{$\begin{array}{l}\text { HBV DNA - } \log _{10} \text { copies } / \mathrm{mL} \\
\text { Total bilirubin }(\mu \mathrm{mol} / \mathrm{L})\end{array}$} & & $3.94 \pm 1.36$ \\
\hline & $\leq 20$ & $82(79.6)$ \\
\hline & $>20$ & $21(20.4)$ \\
\hline \multirow{2}{*}{ Direct bilirubin $(\mu \mathrm{mol} / \mathrm{L})$} & $\leq 7$ & $75(72.8)$ \\
\hline & $>7$ & $28(27.2)$ \\
\hline \multirow{2}{*}{ Albumin $(\mathrm{g} / \mathrm{L})$} & $35-55$ & $93(90.3)$ \\
\hline & $<35$ OR $>55$ & $10(9.7)$ \\
\hline \multirow{2}{*}{$\operatorname{AFP}(\mathrm{ng} / \mathrm{mL})$} & $\leq 20$ & $42(40.8)$ \\
\hline & $>20$ & $61(59.2)$ \\
\hline AL T (U/L) & $\leq 42$ & $55(53.4)$ \\
\hline ALI (U/L) & $>42$ & $48(46.6)$ \\
\hline AST (U/L) & $\leq 37$ & $48(46.6)$ \\
\hline $\mathrm{ASI}(\mathrm{U} / \mathrm{L})$ & $>37$ & $55(53.4)$ \\
\hline GGT (U/L) & $\leq 61$ & $50(48.5)$ \\
\hline (U) (U/L) & $>61$ & $53(51.5)$ \\
\hline ALP (U/L) & $\leq 129$ & $84(81.6)$ \\
\hline
\end{tabular}




\begin{tabular}{lcc} 
& $>129$ & $19(18.4)$ \\
Follow-up time (month) & Median & 30.97 \\
\multirow{2}{*}{ HCC-related death } & IQR & $11.67-59.66$ \\
& No & $41(39.8)$ \\
Recurrence & Yes & $62(60.2)$ \\
& No & $30(29.1)$ \\
\hline
\end{tabular}

†Plus/minus values are means $\pm \mathrm{SD}$; Data are number (\%), unless otherwise indicated.

ALP, alkaline phosphatase; ALT, alanine aminotransferase; AST, aspartate aminotransferase; BMI, body mass index; GGT, $\gamma$-glutamyltranspeptidase; HBV, hepatitis $B$ virus; $\mathrm{HCC}$, hepatocellular carcinoma.

3.47, $p=0.001$ ) (Supplementary Figure 2). Next, we investigated the associations of the combined HBV variant with clinical variables. It was found that the combined variant in the sera was significantly associated with microscopic vascular invasion $(p<0.001)$, larger tumor size $(p=0.019)$, and higher levels of $\gamma$-glutamyltranspeptidase (GGT) and alkaline phosphatase (ALP) $\left(p=1.15 \times 10^{-3}\right.$ for GGT and $p<0.001$ for ALP) (Table 2). We failed to perform stratified analysis for these two variants in the sera of HBV
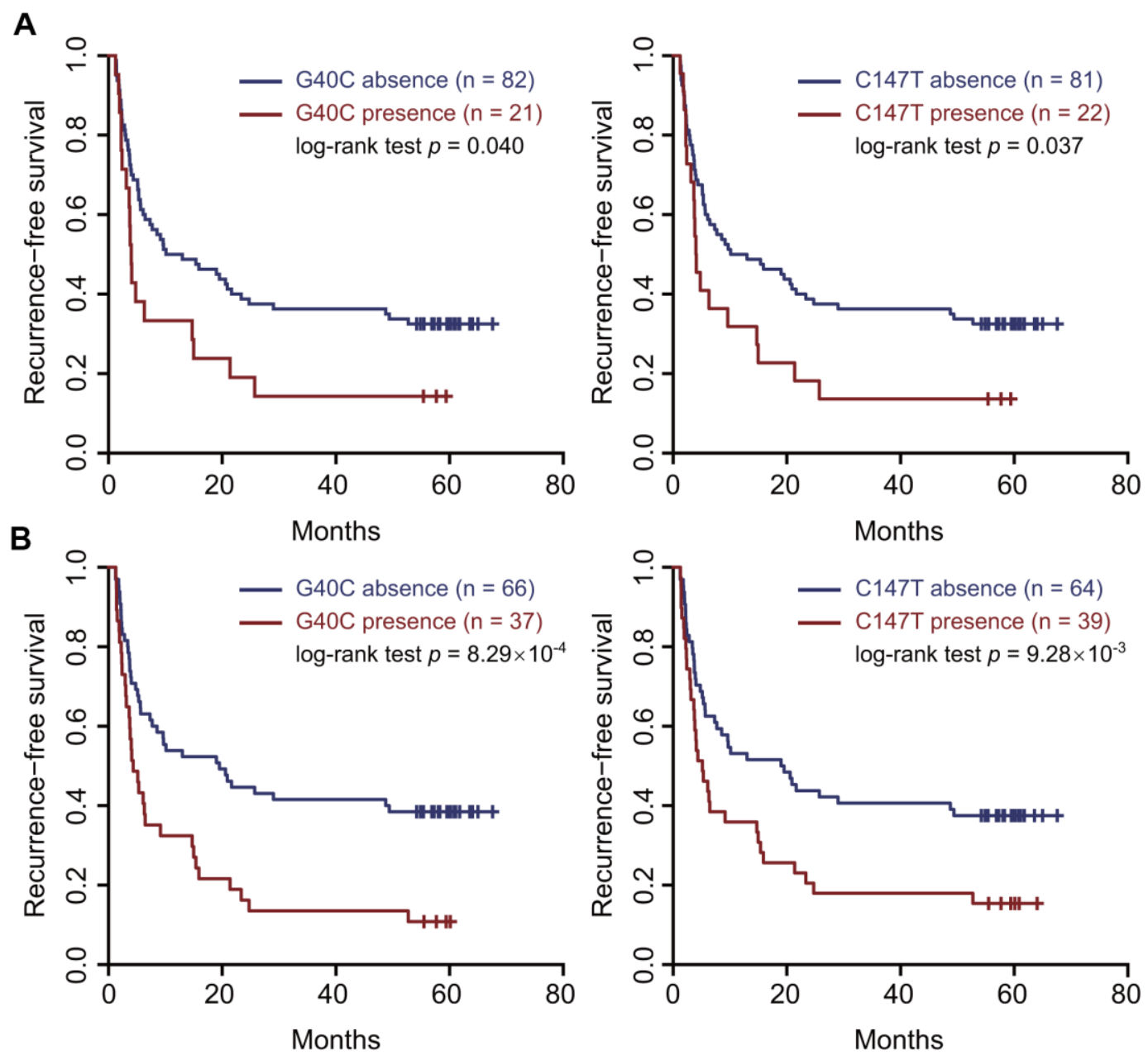

Figure 1. Two HBV preS variants in the tumor tissues and sera predicted an unfavorable recurrence-free survival. (A) the tumor tissues. (B) the sera. Patients were split into two groups according to the presence (or absence) of the variant. Kaplan-Meier curves were plotted to visualize the difference. 
Table 2. Association of the combined HBV variant with clinical variables ${ }^{\dagger}$.

\begin{tabular}{lcccc}
\hline \multirow{2}{*}{ Variable } & \multirow{2}{*}{ Level } & \multicolumn{3}{c}{ The presence of the two HBV variants } \\
\cline { 3 - 5 } & & No & Yes & \multicolumn{1}{c}{$\boldsymbol{P}$ value } \\
\hline \multirow{2}{*}{ Microscopic vascular invasion } & No & $50(48.5)$ & $15(14.6)$ & $8.35 \times 10^{-4}$ \\
Tumor size (cm) & Yes & $16(15.5)$ & $22(21.4)$ & 0.019 \\
GGT (U/L) & & $5.89 \pm 3.09$ & $7.78 \pm 3.88$ & $1.52 \times 10^{-4}$ \\
ALP (U/L) & & $86.3 \pm 99.0$ & $148.9 \pm 122.2$ & $1.15 \times 10^{-3}$ \\
\hline
\end{tabular}

†Plus/minus values are means \pm SD; Data are number (\%), unless otherwise indicated. Wilcoxon rank sum test was performed for continuous variables. Chi-square test was applied for count data. The two HBV variants (G40C and C147T) were combined. GGT, $\nu$-glutamyltranspeptidase; ALP, alkaline phosphatase.

genotype $\mathrm{C}$, as these variants were barely present in the samples (1/67 for G40C and 3/67 for C147T). We also scanned all the preS2 deletion sites in our data. It was found that pre-S2 deletion mutants were present in 85 sera and 87 tumor samples, respectively. However, preS2 deletion mutants were not associated with prognosis of HCC patients in our data (Supplementary Figure 3).

All virological factors including HBV genotype and HBV variants and clinicopathological factors were subjected to the Cox proportional hazard model analysis to estimate postoperative survival. Significant variables in the univariate Cox regression analysis were included in the multivariate Cox model. The results show that tumor rupture $(\mathrm{HR}=3.91,95 \% \mathrm{CI}=1.14-13.35, p=0.03)$, microscopic vascular invasion $(\mathrm{HR}=3.03,95 \%$ $\mathrm{CI}=1.72-5.34, \quad p<0.001), \quad \alpha$-fetoprotein $\quad$ (AFP) $(\mathrm{HR}=1.88,95 \% \mathrm{CI}=1.04-3.38, p=0.036)$, and ALP $(\mathrm{HR}=2.5,95 \% \mathrm{CI}=1.39-4.49, p=0.002)$ increased the risk of $\mathrm{HCC}$ recurrence, while age $(\mathrm{HR}=0.97,95 \%$ $\mathrm{CI}=0.94-0.99, \quad p=0.024)$ and antiviral treatment $(\mathrm{HR}=0.15,95 \% \mathrm{CI}=0.08-0.28, p<0.001)$ significantly decreased the risk of HCC recurrence (Supplementary Table 4). Because antiviral therapy is a very strong protective factor to prevent the recurrence of $\mathrm{HCC}$, the multivariate Cox proportional hazard models were further stratified by antiviral treatment. The results show that $\mathrm{G} 40 \mathrm{C} \quad(\mathrm{HR}=3.89,95 \% \mathrm{CI}=1.39-10.87$, $p=0.01)$, advanced BCLC staging ( $\mathrm{HR}=4.63,95 \%$ $\mathrm{CI}=1.53-14.02, p=0.007)$, and high level of AFP $(\mathrm{HR}=5.88,95 \% \mathrm{CI}=1.88-18.39, p=0.002)$ significantly increased the risk of $\mathrm{HCC}$ recurrence in the group with postoperative antiviral treatment; however, G40C was not associated with postoperative recurrence in $\mathrm{HCC}$ patients without postoperative antiviral treatment (Supplementary Table 5).

Next, each clinical variable and the two HBV variants were introduced into the Cox proportional hazards model to build a model that could predict postoperative recurrence of $\mathrm{HCC}$. It was found that the model consisting of serum AFP and G40C achieved the best performance (area under curve (AUC) $=0.79$, sensitivity $=0.80$, and specificity $=0.70$ ). In this model, AFP was further discretized to achieve a better performance (Table 3 ). If the model was built by dichotomized AFP $(\leq 20$ or $>20 \mathrm{ng} / \mathrm{mL})$ alone, the prediction power was less optimal $(\mathrm{AUC}=0.73$, sensitivity $=0.75$, specificity $=0.70$ ) (Figure 2). The statistical test suggested that the AUC of the model containing AFP and G40C was significantly larger than that of the model containing AFP alone $(p=0.029)$.

\section{Gene dysregulation and biological functions related to the two HBV variants}

In the RNA-seq data, the correlation of these two HBV variants in the tumors was 0.99 (Figure 3A), which was quite consistent with the Sanger sequencing data. Furthermore, each of the variants could be identified in almost each read covering this HBV nucleotide in any positive sample. Based on this observation, the tumors in RNA-seq dataset were split into two groups: tumors with high and low frequencies of these variants. In total, 109 tumor samples with sufficient coverage on these variants were retained for differential expression analysis. It was found that 169 genes were differentially expressed between the two groups. Among these genes, 114 were upregulated, while 55 downregulated in the tumors with high frequencies of the HBV variants (Figure 3B and Supplementary Table 6). We observed that the HBV $S$ gene was upregulated in the tumors with high frequency of the $\mathrm{HBV}$ variants (fold change = 6.82, FDR $=0.028$, Figure 3B, 3C). G40C and C147T were located at the promoter region of the HBV S gene. Therefore, transcription factor binding sites (TFBSs) were predicted for the promoter region (nt. 1 to nt. 154 of the HBV genome). Multiple possible TFBSs were discovered at this region. These data suggest that the variants might be involved in regulating the transcription of HBV S gene (Supplementary Table 7).

Next, gene set enrichment analysis (GSEA) was performed to investigate the gene sets enriched between 
Table 3. Risk scores of HCC recurrence based on the presence of G40C and discretized AFP levelst.

\begin{tabular}{lccc}
\hline AFP $(\mathbf{n g} / \mathbf{m L})$ & Discretized AFP & G40C & Score \\
\hline$<20$ & 0 & 0 & 0 \\
$\geq 20$ and $<200$ & 1 & 0 & 1.365 \\
$\geq 200$ and $<400$ & 2 & 0 & 2.730 \\
$\geq 400$ & 3 & 0 & 4.095 \\
$<20$ & 0 & 1 & 2.000 \\
$\geq 20$ and $<200$ & 1 & 1 & 3.361 \\
$\geq 200$ and $<400$ & 2 & 1 & 4.727 \\
$\geq 400$ & 3 & 1 & 6.092 \\
\hline
\end{tabular}

†AFP, $\alpha$-fetoprotein; HCC, hepatocellular carcinoma.

these two groups of tumors. In total, 47 positively and 5 negatively enriched gene sets were identified in the data (Supplementary Table 8). In the five negatively enriched gene sets, the top ranked gene set suggested that these $\mathrm{HBV}$ variants were associated with proliferation and chromosome instability (CHIANG_LIVER_CANCER_ SUBCLASS_PROLIFERATION_DN, normalized enrichment score (NES) $=-2.73$, familywise-error rate (FWER) < 0.001) (Figure 3D). In addition, its complementary gene set "CHIANG_LIVER_CANCER_ SUBCLASS _ PROLIFERATION UP" was enriched positively in the data (NES $=2 . \overline{6} 2$, FWER $<0.001$ ) (Supplementary Table 8). Another top ranked negatively enriched gene set was "CHIANG_LIVER_CANCER SUBCLASS_CTNNB1_UP” $(\mathrm{NES}=-2.66$, FWER <
0.001), which confirmed the results of our survival analyses (Figure 3E). Besides these gene sets, other prognosis-predicting gene sets were significantly enriched, including LEE_LIVER_CANCER SURVIVAL_UP (NES $=-2.32$, FWER $=0.005)$ and LEE_LIVER_CANCER_SURVIVAL_DN $(\mathrm{NES}=2.39$, FWER $=0.001$ ), indicating that the HBV variants predicted unfavorable OS. In addition, SOTIRIOU_BREAST_CANCER_GRADE_1_VS_3_UP $($ NES $=2.41 ;$ FWER $<0.001)$ and VILLANUEVA _LIVER_CANCER_KRT19_UP $($ NES $=2.16$, FWER = 0.01) were significantly enriched, indicating that the two HBV variants facilitate metastasis. Our results also suggest that these HBV variants are associated with tumorigenesis, anticancer drug resistance, and interferon
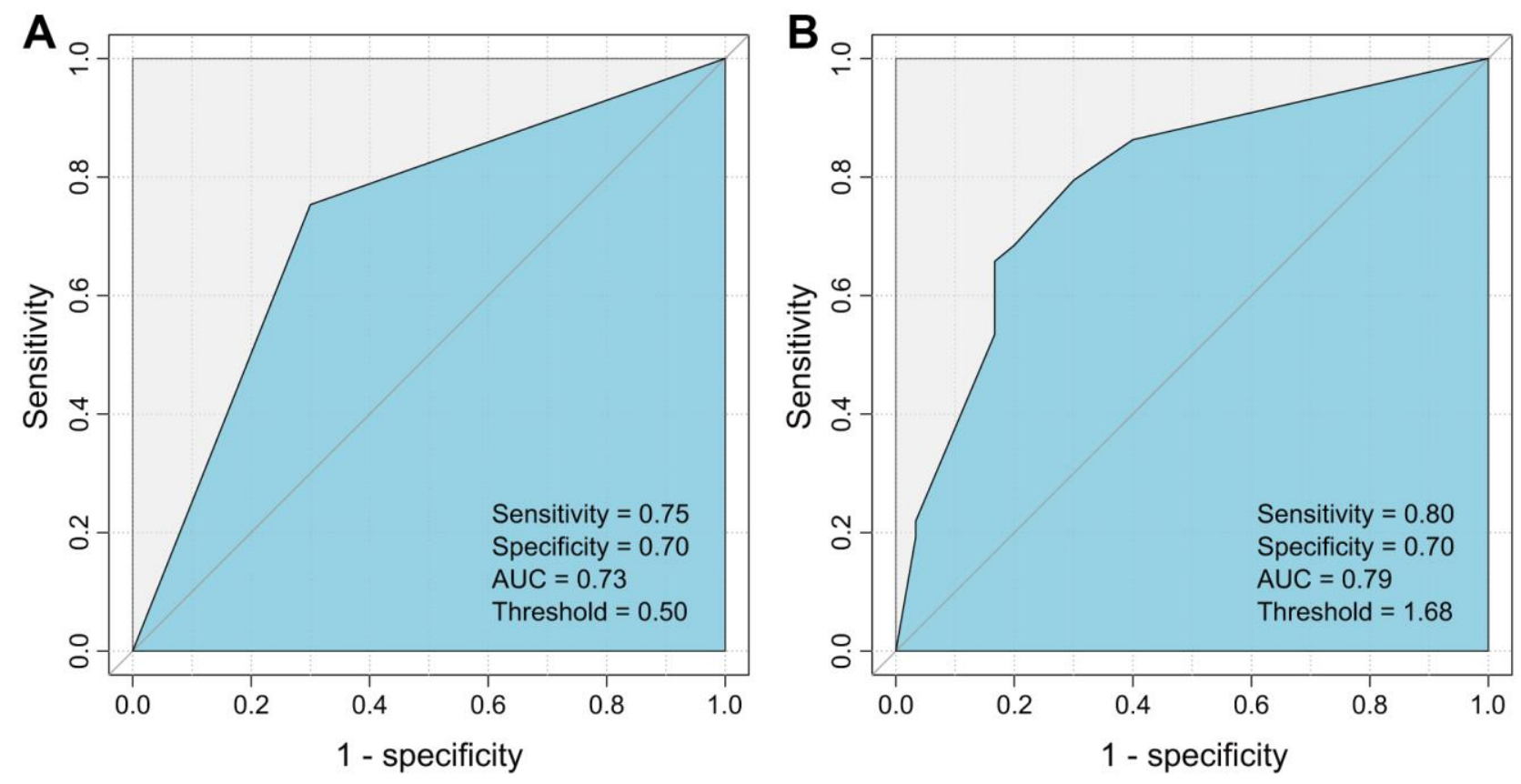

Figure 2. ROC curves for the HCC recurrence prediction models using AFP alone and AFP plus G40C. (A) Model using AFP alone. (B) Model using AFP and G4OC. ROC, receiver operating characteristic; AFP, $\alpha$-fetoprotein; HCC, hepatocellular carcinoma. 
response (BOYAULT_LIVER_CANCER_SUBCLASS G3 UP, NES $=2.41, \quad$ FWER $=0.001$; KOBAYASHI_EGFR_SIGNALING_24HR_DN, NES = 2.32, FWER $=0.001 ;$ and FARMER_BREAST CANCER_CLUSTER_1, NES $=-2.15$, FWER $=0.051$ ) (Figure 3F and Supplementary Table 8).

\section{DISCUSSION}

In this study, RNA-seq datasets of 203 HCC samples were firstly screened for HCC prognosis-related HBV variants in the preS region. A total of 12 variants related to RFS were initially identified. Of those, G40C and
C147T were successfully validated both in the sera and in the tumors of $103 \mathrm{HBV}-\mathrm{HCC}$ patients in our prospective cohort. Interestingly, the two variants were actually polymorphic sites between the genomes of HBV genotypes B2 and C2 and highly linked with each other, either in the RNA-seq data of the tumor tissues or in the Sanger sequencing data of both the sera and the tumor tissues. G40C is also a representative of HBV genotype B2 or genotype mixture with genotype B2. Compared to genotype $\mathrm{C} 2, \mathrm{HBV}$ genotype $\mathrm{B} 2$ or genotype mixture increases the risk of $\mathrm{HCC}$ recurrence, which is concordant with our previous study [15]. The results of multivariate Cox proportional hazard models
A
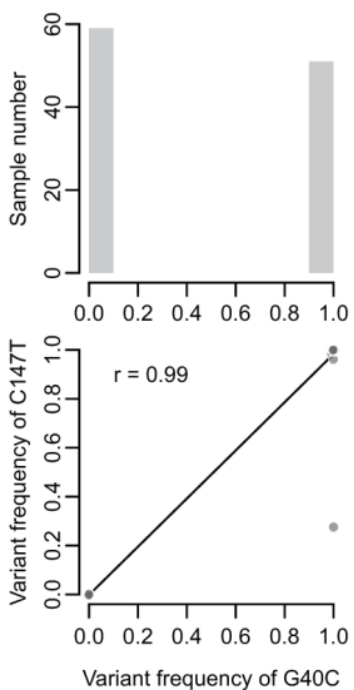

D

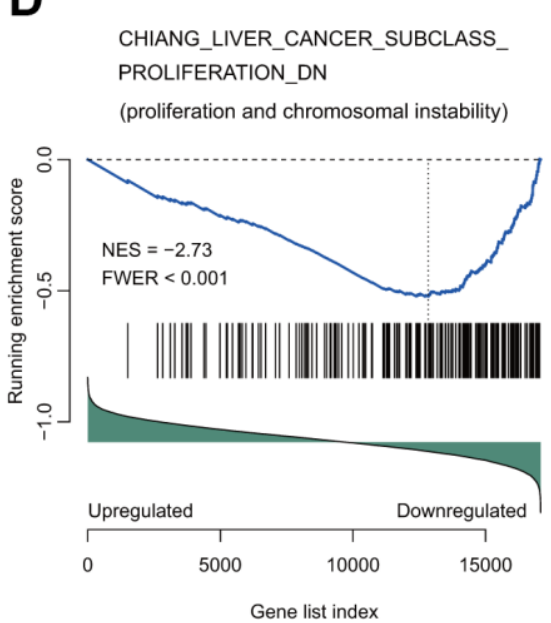

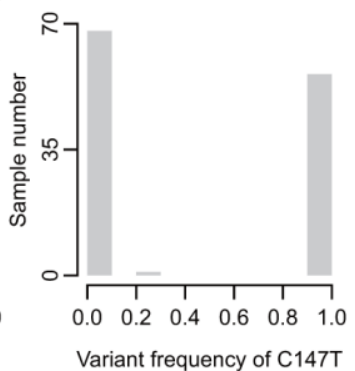

B

E

CHIANG_LIVER_CANCER_SUBCLASS_CTNNB1_UP (recurrence-free survival)

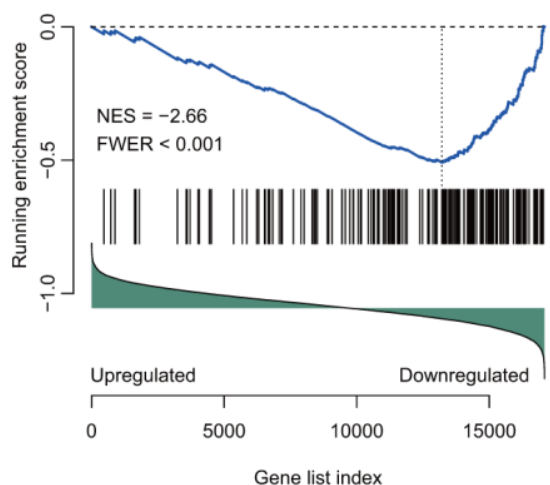

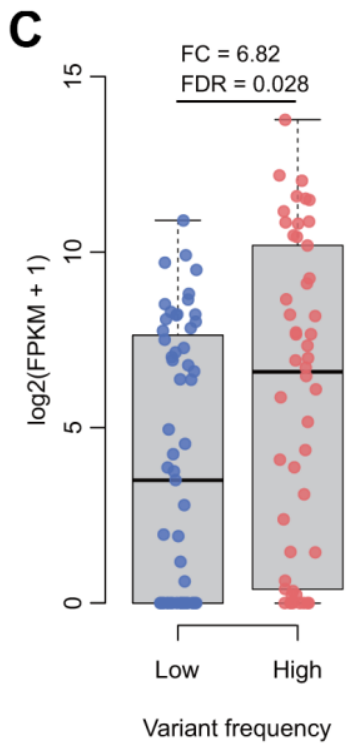

$\mathbf{F}$

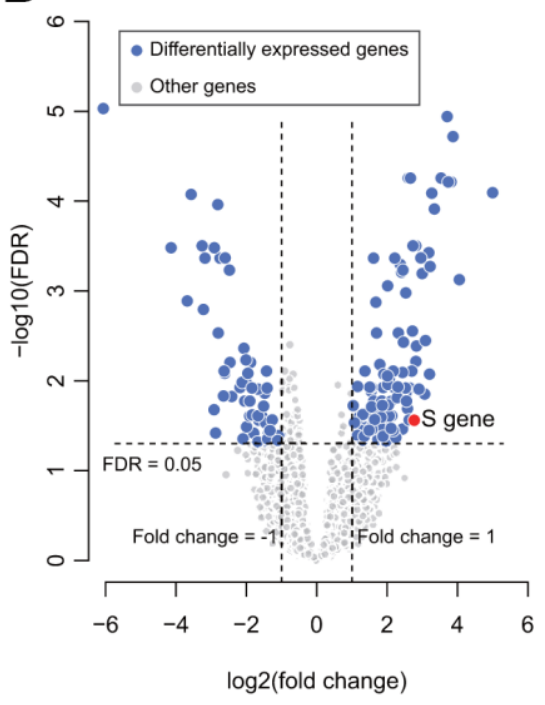
BOYAULT_LIVER_CANCER_SUBCLASS_G3_UP

Figure 3. Correlation of the two variants and their functional analysis in RNA-seq data of HBV-HCC tumors. (A) The correlation (lower triangle) and frequency distributions (diagonal) of these two variants. The two variants tended to occur simultaneously. (B) Volcano plot for differentially expressed genes between groups with high or low frequency of the two variants. (C) The HBV S gene was significantly upregulated. (D) The gene set represents the gene signature of proliferation and chromosome instability. (E) The gene set represents the gene signature of recurrence-free survival. (F) The gene set represents the gene signature of tumorigenesis. NES, normalized enrichment score. FWER, familywise-error rate. 
show that G40C, advanced BCLC staging, and high level of AFP significantly increased the risk of HCC recurrence in the group with postoperative antiviral treatment, while there was no effect in the group without postoperative antiviral treatment (Supplementary Table 5). Antiviral treatment can decrease the occurrence and recurrence of $\mathrm{HCC}$ in high-risk HBVinfected subjects $[14,16,17]$. This result indicates that postoperative antiviral treatment could not decrease the risk of $\mathrm{HCC}$ recurrence in patients with $\mathrm{HBV}$ genotype B carrying G40C.

Our results show that $\mathrm{G} 40 \mathrm{C}$ as a represent of $\mathrm{C} 147 \mathrm{~T}$ and HBV genotype B2 was a significant serological biomarker for HCC recurrence. AUC of the optimized model consisting of HBV G40C and AFP in the sera was 0.79 . The prediction power of this prediction model is better than the one we previously developed using clinical variables composed of the levels of HBV DNA load, the presence of liver cirrhosis, the level of AFP, and BCLC stage [18]. Furthermore, the Cox prediction model based on the AJCC tumor stage and ratios of serum preS2 deletion as deleted by a preS gene chip was also developed for the prediction of postoperative prognosis in HBV-HCC $[12,19]$. It has been confirmed that the AUC of this model is 0.741 in the main cohort and 0.704 in the validation cohort [12]. Apparently, our model established in this study should be more powerful than the currently published ones in predicting postoperative prognosis in HBV-HCC. This model is worth translating into clinical practice.

Some studies have confirmed the carcinogenic potential of the preS2 mutated proteins in both transgenic mice and cell culture $[7,20,21]$. The rtM204I/sW196* $\mathrm{preS} / \mathrm{S}$ truncation induce the cell transformation and tumorigenesis ability via altered host gene expressions, including MGST2, HIF1A, and TGFbi. Downregulated TGFbi may be a common mechanism for oncogenicity in HBV surface truncation mutants [22]. PreS2 deletions modulate cellular processes with a potential impact on liver disease. The accumulation of mutated envelope proteins in the ER leads to ER stress, DNA damage, centrosome overduplication, and genomic instability [23-25]. HBV preS2 interacted with the preS2-responsible region and activated the hTERT promoter, resulting in the upregulation of telomerase activity and the promotion of HCC development [22]. However, the mechanism by which the nucleotide variants in the preS2 of $\mathrm{HBV}$ promote the recurrence of HCC remains unknown. G40C and C147T are located in the HBV preS2 region and as well as the promoter region of the HBV S gene. The expression of the HBV $S$ gene was upregulated 6.82 times in the tumors with high frequency of the two variants, compared to those with low frequency of the two variants (Figure 3C). The
HBV variants may alter the binding of the TFBSs to the promoter, which regulates the transcription of HBV S gene (Supplementary Table 7). In this study, we also provided evidence showing that the two HBV variants facilitated cell proliferation, chromosome instability, tumorigenesis, metastasis, and anticancer drug resistance. It may explain the reason that $\mathrm{HBV}$ Genotype B2 increases the risk of HCC recurrence. Further experimental studies using cell lines and animal models are suggested to validate the cancer promoting function of the HBV with the two variants.

In summary, the present study indicates that HBV preS variants $\mathrm{G} 40 \mathrm{C}$ and $\mathrm{C} 147 \mathrm{~T}$ as representatives of $\mathrm{HBV}$ Genotype B2 are highly linked with each other, and may serve as prognostic biomarkers in both sera and tumor tissue samples of HBV-HCC patients. The AUC of the optimized model combining G40C with AFP was 0.79 . HBV preS G40C variant and serological AFP are easily examined in HBV-HCC patients and helpful for making therapeutic decision before surgery. Thus, the model is worth translating into clinical practice.

\section{MATERIALS AND METHODS}

\section{RNA-seq data analysis to screen for HBV variants related to $\mathrm{HCC}$ prognosis}

The original RNA-seq data of 203 HCC patients from 12 studies (SRP062885, SRP069212, SRP099053, SRP174991, SRP256409, SRA074279, SRP039694, SRP108560, SRP118972, SRP120360, SRP188371, and SRP220071) were retrieved from the Sequence Read Archive database [26-34]. HBV variants in the region of preS1/preS2 were extracted as previously described and those with average frequencies $\geq 25 \%$ and more than 100 valid values were kept for downstream analyses [35]. The read count matrix was obtained by Salmon [36]. During the process, the annotation of human genes was combined with that of HBV ones. Thus, the abundances of HBV genes were evaluated along with the human genes during the quantification process. Combat-Seq method was applied to adjust the potential batch effect among different studies [37]. The gene set names containing "survival" (or "recurrence") and "liver cancer" were retrieved from gene sets of chemical and genetic perturbations in MsigDB (http://software.broadinstitute.org/gsea/index.jsp) as liver-specific prognosis-related gene sets. Sample-level prognosis scores were calculated by gene set variation analysis in which classical maximum deviation method was performed to compute the enrichment statistics [38]. The parameter "min.sz" was set to 10 during the process. The function "cor.test" in $\mathrm{R}$ language was applied to calculate the Pearson correlations between variant frequencies of $\mathrm{HBV}$ loci and prognosis scores. 
The Benjamini-Hochberg (BH) method was performed among the prognostic gene sets per variant to calculate FDRs. Any association with FDR $<0.1$ was kept for downstream analyses. For differential expression gene analysis, edgeR was applied $[39,40] . P$ values were adjusted by $\mathrm{BH}$ method. Genes with fold change $\geq 2$ and FDR $<0.05$ were collected as differentially expressed genes. For GSEA analysis, the gene's read count was converted into Fragments Per Kilobase of exon model per Million mapped fragments (FPKM). Taking the signal-to-noise ratio as input, the "GSEAPreranked" tool in GSEA software was performed to detect the gene sets enriched in the data [41]. Gene sets with FWER $\leq 0.1$ were considered as significantly enriched.

\section{Independent validation of the $\mathrm{HBV}$ variants in $\mathrm{HBV}$ - HCC patients}

In total, 103 consecutive $\mathrm{HBV}$-infected $\mathrm{HCC}$ patients who received radical hepatectomy from this research group of the Eastern Hepatobiliary Surgery Hospital (Shanghai, China) were enrolled and confirmed by pathology from February 2011 to March 2012. Resected tumors were subjected to pathological examination for tumor-free resection margin $>1 \mathrm{~cm}$ without evidence of cancer metastasis. Preoperative peripheral blood samples and tumor tissues of participants were collected and stored at $-80^{\circ} \mathrm{C}$ immediately after surgery. Routine laboratory tests related to liver function were measured using international standard methods and matched reagents (HITACHI 7600, Hitachi Koki Co. Ltd., Hitachinaka City, Japan; Wako Diagnostics Reagents, Wako Pure Chemical Industries Ltd., Osaka, Japan). Alpha-fetoprotein concentrations were routinely measured on the Cobas e601 immunoassay analyzers and matched reagents (Roche Diagnostics, Manheim, Germany) with electrochemiluminescence technology. Participants were surgically treated and followed-up according to the standard protocols as previously described [14]. The follow-up was finished on October $1^{\text {st }}$, 2019. All participants were self-reported Han Chinese. This study was approved by the ethics committee of Eastern Hepatobiliary Surgery Hospital. All patients provided written informed consent.

HBV DNA of preoperative sera and tumors was extracted using QIAamp DNA blood mini kit (Qiagen, Hilden, Germany). The HBV genome between nt.2743 and nt.255 (from nt.2743 to nt.3215 and from nt.1 to nt.255) was amplified using nested PCR and sequenced using the cloning-based sequencing method as previously described [42]. Ten clones of each sample were randomly selected for Sanger sequencing. Genotyping was performed by HBV subtype analyzer (STAR) as previously described [35]. For a clone, scores were assigned for Genotype A to $\mathrm{H}$. The genotype of a clone was identified as the one with the largest score. Samples with clones of multiple genotypes were defined as mixture. Variants of each clone and preS2 deletion sites were retrieved from BLAST alignments [43]. Clones that failed to align to the HBV genome were excluded from the subsequent analysis. Sample-level variants were then summarized via collecting the variants of all clones in a sample. In simple terms, in any clone of a sample, if a variant was detected at a nucleotide of the HBV genome, then we considered that the variant was present at that locus in that sample. The pairwise distances of the clones from serum samples were calculated by MEGA $X$ and then visualized to inspect identical clones and therefore inter-subject contamination [44].

\section{Statistical analysis}

Clinical and baseline characteristics were summarized by using mean values with standard deviation or median values with interquartile range (IQR, 25th to 75th percentiles) for continuous variables. Proportions were applied for categorical values. Univariate Cox regression analysis and log-rank test were applied to estimate the associations between the presence of the viral variants and patients' OS and RFS. Kaplan-Meier method performed survival analysis and generated a survival plot. The selected HBV variants and each clinical variable were subjected to the Cox regression analyses to compute the risk scores and build HCC recurrence prediction models. Given that $x_{i}$ is the $i$ th variable and $\beta_{i}$ is its coefficient, then the risk score of a patient is calculated as:

$$
\text { Risk Score }=\sum_{i=1}^{n} \beta_{i} \chi_{i}
$$

The number of variables (i.e., $n$ in the formula) was set to 2 according to the Harrell's guidelines [45]. The best one was determined by the AUC. The receiver operating characteristic (ROC) curves were plotted by $\mathrm{R}$ package pROC [46]. The statistical significance between two AUCs was determined by the one-sided test applied by the function "roc.test" in the pROC package with default parameters. TFBS were predicted by Find Individual Motif Occurrences [47]. The match $p$-value was set to 0.001 to gain more sensitivity. TFBSs with false discovery rate (FDR) of $<0.25$ and overlap with G40C or C147T were collected. For clinical variable association test, differences were determined by Wilcoxon rank sum test or $\chi^{2}$ tests as appropriate. $\mathrm{P}<0.05$ was considered significant. All analyses were two-side and performed using SPSS, version 21 (Armonk, NY). 


\section{Ethics committee approval}

The study protocol conformed to the ethical guidelines of the 1975 Declaration of Helsinki and was approved by the ethics committee of Eastern Hepatobiliary Surgery Hospital. All patients provided written informed consent.

\section{Availability of data and materials}

The sequences of clone sequencing were deposited in GenBank with accession numbers MW179612 MW180878.

\section{AUTHOR CONTRIBUTIONS}

Yin and Cao had full access to all of the data in the study and take responsibility for the integrity of the data and the accuracy of the data analysis. Concept, design and supervision: Yin and Cao; Acquisition, analysis, or interpretation of data: Chen, $\mathrm{Li}$, Zhang (MZ), Pu, Wu, Ding, Cai, Zhang (HZ), Zhao and Yin; Drafting of the manuscript: Chen, Yin and Cao; Critical revision of the manuscript for important intellectual content: All authors. Statistical analysis: Yin, Chen and $\mathrm{Pu}$; Obtained funding: Cao, Yin and Chen; Material support: Li, Zhang (MZ).

\section{CONFLICTS OF INTEREST}

The authors declare that they have no conflicts of interest.

\section{FUNDING}

This work was funded by National Natural Science Foundation of China (81520108021, 91529305, $81673250,81521091,81373067,81502882)$, the State Key Infection Disease Project of China (2017ZX10201201-006-001) and the National Key Basic Research Program (973 program) (2015CB554000).

\section{Editorial note}

\&This corresponding author has a verified history of publications using a personal email address for correspondence.

\section{REFERENCES}

1. Villanueva A. Hepatocellular Carcinoma. N Engl J Med. 2019; 380:1450-62. https://doi.org/10.1056/NEJMra1713263 PMID:30970190

2. Yin J, Xie J, Liu S, Zhang H, Han L, Lu W, Shen Q, Xu G,
Dong $\mathrm{H}$, Shen J, Zhang J, Han J, Wang L, et al. Association between the various mutations in viral core promoter region to different stages of hepatitis B, ranging of asymptomatic carrier state to hepatocellular carcinoma. Am J Gastroenterol. 2011; 106:81-92.

https://doi.org/10.1038/ajg.2010.399 PMID:20959817

3. Huang $\mathrm{Y}$, Tai AW, Tong S, Lok AS. HBV core promoter mutations promote cellular proliferation through E2F1mediated upregulation of S-phase kinase-associated protein 2 transcription. J Hepatol. 2013; 58:1068-73. https://doi.org/10.1016/i.jhep.2013.01.014 PMID:23348237

4. Revill PA, Tu T, Netter HJ, Yuen LK, Locarnini SA, Littlejohn $M$. The evolution and clinical impact of hepatitis B virus genome diversity. Nat Rev Gastroenterol Hepatol. 2020; 17:618-34. https://doi.org/10.1038/s41575-020-0296-6 PMID: $\underline{2467580}$

5. Yin J, Xie J, Zhang H, Shen Q, Han L, Lu W, Han Y, Li C, $\mathrm{Ni}$ W, Wang H, Cao G. Significant association of different preS mutations with hepatitis B-related cirrhosis or hepatocellular carcinoma. J Gastroenterol. 2010; 45:1063-71. https://doi.org/10.1007/s00535-010-0253-1 PMID:20419326

6. Zheng Y, Qian YY, Fan H. Pre-S2 and HBV associated hepatocellular carcinoma. Hepatoma Res. 2018; 4:17. https://doi.org/10.20517/2394-5079.2018.08

7. Wang HC, Huang W, Lai MD, Su IJ. Hepatitis B virus pre$S$ mutants, endoplasmic reticulum stress and hepatocarcinogenesis. Cancer Sci. 2006; 97:683-88. https://doi.org/10.1111/j.1349-7006.2006.00235.x PMID:16863502

8. Ding $\mathrm{H}, \mathrm{Tu} \mathrm{H}, \mathrm{Qu} \mathrm{C}$, Cao $\mathrm{G}$, Zhuang $\mathrm{H}$, Zhao $\mathrm{P}, \mathrm{Xu} X$, Yang $\mathrm{Y}, \mathrm{Lu} \mathrm{S}$, and Committee for Prevention and Control of Hepatobiliary and Pancreatic Diseases of Chinese Preventive Medicine Association, and Committee of Hepatology of Chinese Research Hospital Association, and Hepatology Society of Chinese Medical Association, and Prevention of Infection Related Cancer (PIRCA) Group. Guideline for stratified screening and surveillance in patients with high risk of primary liver cancer (2020). Hepatoma Res. 2021; 7:17. https://doi.org/10.20517/2394-5079.2021.13

9. Liu WC, Wu IC, Lee YC, Lin CP, Cheng JH, Lin YJ, Yen CJ, Cheng PN, Li PF, Cheng YT, Cheng PW, Sun KT, Yan SL, et al. Hepatocellular carcinoma-associated singlenucleotide variants and deletions identified by the use of genome-wide high-throughput analysis of hepatitis B virus. J Pathol. 2017; 243:176-92. https://doi.org/10.1002/path.4938 
PMID:28696069

10. Zhang AY, Lai CL, Huang FY, Seto WK, Fung J, Wong DK, Yuen MF. Evolutionary Changes of Hepatitis B Virus Pre-S Mutations Prior to Development of Hepatocellular Carcinoma. PLoS One. 2015; 10:e0139478.

https://doi.org/10.1371/journal.pone.0139478 PMID:26421619

11. Su CW, Chiou YW, Tsai YH, Teng RD, Chau GY, Lei HJ, Hung $\mathrm{HH}$, Huo $\mathrm{TI}, \mathrm{Wu}$ JC. The Influence of Hepatitis B Viral Load and Pre-S Deletion Mutations on PostOperative Recurrence of Hepatocellular Carcinoma and the Tertiary Preventive Effects by Anti-Viral Therapy. PLoS One. 2013; 8:e66457.

https://doi.org/10.1371/journal.pone.0066457 PMID:23805222

12. Yen CJ, Ai YL, Tsai HW, Chan SH, Yen CS, Cheng KH, Lee YP, Kao CW, Wang YC, Chen YL, Lin CH, Liu T, Tsai HP, et al. Hepatitis $B$ virus surface gene pre- $S_{2}$ mutant as a high-risk serum marker for hepatoma recurrence after curative hepatic resection. Hepatology. 2018; 68: 815-26.

https://doi.org/10.1002/hep.29790

PMID:29350774

13. Tsai HW, Lin YJ, Lin PW, Wu HC, Hsu KH, Yen CJ, Chan $\mathrm{SH}$, Huang W, Su IJ. A clustered ground-glass hepatocyte pattern represents a new prognostic marker for the recurrence of hepatocellular carcinoma after surgery. Cancer. 2011; 117:2951-60. https://doi.org/10.1002/cncr.25837 PMID:21692054

14. Yin J, Li N, Han Y, Xue J, Deng Y, Shi J, Guo W, Zhang H, Wang $\mathrm{H}$, Cheng S, Cao G. Effect of antiviral treatment with nucleotide/nucleoside analogs on postoperative prognosis of hepatitis B virus-related hepatocellular carcinoma: a two-stage longitudinal clinical study. J Clin Oncol. 2013; 31:3647-55.

https://doi.org/10.1200/JCO.2012.48.5896

PMID:24002499

15. Yin J, Zhang H, Li C, Gao C, He Y, Zhai Y, Zhang P, Xu L, Tan X, Chen J, Cheng S, Schaefer S, Cao G. Role of hepatitis $B$ virus genotype mixture, subgenotypes $C 2$ and B2 on hepatocellular carcinoma: compared with chronic hepatitis B and asymptomatic carrier state in the same area. Carcinogenesis. 2008; 29:1685-91.

https://doi.org/10.1093/carcin/bgm301

PMID:18192693

16. Yin J, Wang J, Pu R, Xin H, Li Z, Han X, Ding Y, Du Y, Liu W, Deng $Y$, Ji $X, W u M, Y u M$, et al. Hepatitis B Virus Combo Mutations Improve the Prediction and Active Prophylaxis of Hepatocellular Carcinoma: A ClinicBased Cohort Study. Cancer Prev Res (Phila). 2015; 8:978-88.
https://doi.org/10.1158/1940-6207.CAPR-15-0160 PMID:26290395

17. Lin $\mathrm{CL}$, Kao JH. Prevention of hepatitis B virus-related hepatocellular carcinoma. Hepatoma Res. 2021; 7:9 https://doi.org/10.20517/2394-5079.2020.125

18. Yang F, Ma L, Yang Y, Liu W, Zhao J, Chen X, Wang M, Zhang H, Cheng S, Shen F, Wang H, Zhou W, Cao G. Contribution of Hepatitis B Virus Infection to the Aggressiveness of Primary Liver Cancer: A Clinical Epidemiological Study in Eastern China. Front Oncol. 2019; 9:370.

https://doi.org/10.3389/fonc. 2019.00370

PMID:31179237

19. Shen FC, Su IJ, Wu HC, Hsieh YH, Yao WJ, Young KC, Chang TC, Hsieh HC, Tsai HN, Huang W. A pre-S gene chip to detect pre-S deletions in hepatitis $B$ virus large surface antigen as a predictive marker for hepatoma risk in chronic hepatitis B virus carriers. J Biomed Sci. 2009; 16:84.

https://doi.org/10.1186/1423-0127-16-84

PMID:19751529

20. Luan F, Liu H, Gao L, Liu J, Sun Z, Ju Y, Hou N, Guo C, Liang $X$, Zhang L, Sun W, Ma C. Hepatitis B virus protein pres2 potentially promotes HCC development via its transcriptional activation of hTERT. Gut. 2009; 58:1528-37.

https://doi.org/10.1136/gut.2008.174029 PMID:19651630

21. Yang JC, Teng CF, Wu HC, Tsai HW, Chuang HC, Tsai TF, Hsu YH, Huang W, Wu LW, Su IJ. Enhanced expression of vascular endothelial growth factor-A in ground glass hepatocytes and its implication in hepatitis B virus hepatocarcinogenesis. Hepatology. 2009; 49:1962-71. https://doi.org/10.1002/hep.22889 PMID:19475690

22. Lai MW, Liang KH, Yeh CT. Hepatitis B Virus preS/S Truncation Mutant rtM204I/sW196* Increases Carcinogenesis through Deregulated HIF1A, MGST2, and TGFbi. Int J Mol Sci. 2020; 21:6366.

https://doi.org/10.3390/ijms21176366

PMID:32887289

23. Hsieh YH, Su IJ, Wang HC, Chang WW, Lei HY, Lai MD, Chang WT, Huang W. Pre-S mutant surface antigens in chronic hepatitis $B$ virus infection induce oxidative stress and DNA damage. Carcinogenesis. 2004; 25:2023-32.

https://doi.org/10.1093/carcin/bgh207 PMID:15180947

24. Wang LH, Huang W, Lai MD, Su IJ. Aberrant cyclin A expression and centrosome overduplication induced by hepatitis B virus pre-S2 mutants and its implication in hepatocarcinogenesis. Carcinogenesis. 2012; 33:466-72. 
https://doi.org/10.1093/carcin/bgr296

PMID:22159224

25. Hsieh YH, Chang YY, Su IJ, Yen CJ, Liu YR, Liu RJ, Hsieh WC, Tsai HW, Wang LH, Huang W. Hepatitis B virus pre-S2 mutant large surface protein inhibits DNA double-strand break repair and leads to genome instability in hepatocarcinogenesis. J Pathol. 2015; 236:337-47.

https://doi.org/10.1002/path.4531 PMID:25775999

26. Chiu YT, Wong JK, Choi SW, Sze KM, Ho DW, Chan LK, Lee JM, Man K, Cherny S, Yang WL, Wong CM, Sham PC, Ng 1O. Novel pre-mRNA splicing of intronically integrated HBV generates oncogenic chimera in hepatocellular carcinoma. J Hepatol. 2016; 64: 1256-64.

https://doi.org/10.1016/i.jhep.2016.02.005

PMID:26867494

27. Yang $Y$, Chen L, Gu J, Zhang H, Yuan J, Lian Q, Lv G, Wang S, Wu Y, Yang YT, Wang D, Liu Y, Tang J, et al. Recurrently deregulated IncRNAs in hepatocellular carcinoma. Nat Commun. 2017; 8:14421.

https://doi.org/10.1038/ncomms14421

PMID:28194035

28. Yoo S, Wang W, Wang Q, Fiel MI, Lee E, Hiotis SP, Zhu J. A pilot systematic genomic comparison of recurrence risks of hepatitis B virus-associated hepatocellular carcinoma with low- and high-degree liver fibrosis. BMC Med. 2017; 15:214.

https://doi.org/10.1186/s12916-017-0973-7 PMID:29212479

29. Jiang $Y$, Sun $A$, Zhao $Y$, Ying $W$, Sun $H$, Yang $X$, Xing $B$, Sun W, Ren L, Hu B, Li C, Zhang L, Qin G, et al, and Chinese Human Proteome Project (CNHPP) Consortium. Proteomics identifies new therapeutic targets of early-stage hepatocellular carcinoma. Nature. 2019; 567:257-61.

https://doi.org/10.1038/s41586-019-0987-8

PMID:30814741

30. Kang L, Liu X, Gong Z, Zheng H, Wang J, Li Y, Yang H, Hardwick J, Dai H, Poon RT, Lee NP, Mao M, Peng Z, Chen R. Genome-wide identification of RNA editing in hepatocellular carcinoma. Genomics. 2015; 105:76-82. https://doi.org/10.1016/i.ygeno.2014.11.005 PMID:25462863

31. Gao F, Liang H, Lu H, Wang J, Xia M, Yuan Z, Yao Y, Wang $T$, Tan X, Laurence A, Xu H, Yu J, Xiao W, et al. Global analysis of DNA methylation in hepatocellular carcinoma by a liquid hybridization capture-based bisulfite sequencing approach. Clin Epigenetics. 2015; 7:86. https://doi.org/10.1186/s13148-015-0121-1 PMID:26300991
32. Jin Y, Lee WY, Toh ST, Tennakoon C, Toh HC, Chow PK, Chung AY, Chong SS, Ooi LL, Sung WK, Lee CG. Comprehensive analysis of transcriptome profiles in hepatocellular carcinoma. J Transl Med. 2019; 17:273. https://doi.org/10.1186/s12967-019-2025-x PMID: 31429776

33. Sheng Z, Wang X, Xu G, Shan G, Chen L. Analyses of a Panel of Transcripts Identified From a Small Sample Size and Construction of RNA Networks in Hepatocellular Carcinoma. Front Genet. 2019; 10:431. https://doi.org/10.3389/fgene.2019.00431 PMID:31156698

34. Shen $Y C$, Hsu $C L$, Jeng $Y M$, Ho $M C$, Ho $C M$, Yeh $C P$, Yeh $\mathrm{CY}$, Hsu MC, Hu RH, Cheng AL. Reliability of a singleregion sample to evaluate tumor immune microenvironment in hepatocellular carcinoma. J Hepatol. 2020; 72:489-97. https://doi.org/10.1016/i.jhep.2019.09.032 PMID:31634533

35. Yin J, Chen X, Li N, Han X, Liu W, Pu R, Wu T, Ding Y, Zhang $H$, Zhao J, Han X, Wang $H$, Cheng $S$, Cao G. Compartmentalized evolution of hepatitis $\mathrm{B}$ virus contributes differently to the prognosis of hepatocellular carcinoma. Carcinogenesis. 2021; 42:461-70.

https://doi.org/10.1093/carcin/bgaa127 PMID:33247709

36. Patro R, Duggal G, Love MI, Irizarry RA, Kingsford C. Salmon provides fast and bias-aware quantification of transcript expression. Nat Methods. 2017; 14:417-19. https://doi.org/10.1038/nmeth.4197 PMID:28263959

37. Zhang Y, Parmigiani G, Johnson WE. ComBat-seq: batch effect adjustment for RNA-seq count data. NAR Genom Bioinform. 2020; 2:Iqaa078. https://doi.org/10.1093/nargab/lqaa078 PMID:33015620

38. Hänzelmann S, Castelo R, Guinney J. GSVA: gene set variation analysis for microarray and RNA-seq data. BMC Bioinformatics. 2013; 14:7. https://doi.org/10.1186/1471-2105-14-7 PMID:23323831

39. Lun AT, Chen Y, Smyth GK. It's DE-licious: A Recipe for Differential Expression Analyses of RNA-seq Experiments Using Quasi-Likelihood Methods in edgeR. Methods Mol Biol. 2016; 1418:391-416. https://doi.org/10.1007/978-1-4939-3578-9 19 PMID:27008025

40. McCarthy DJ, Chen Y, Smyth GK. Differential expression analysis of multifactor RNA-Seq experiments with respect to biological variation. Nucleic Acids Res. 2012; 40:4288-97. https://doi.org/10.1093/nar/gks042 PMID:22287627 
41. Subramanian A, Tamayo $P$, Mootha VK, Mukherjee $S$, Ebert BL, Gillette MA, Paulovich A, Pomeroy SL, Golub TR, Lander ES, Mesirov JP. Gene set enrichment analysis: a knowledge-based approach for interpreting genome-wide expression profiles. Proc Natl Acad Sci USA. 2005; 102:15545-50.

https://doi.org/10.1073/pnas.0506580102

PMID:16199517

42. Li Z, Xie Z, Ni H, Zhang Q, Lu W, Yin J, Liu W, Ding Y, Zhao $\mathrm{Y}$, Zhu $\mathrm{Y}$, Pu R, Zhang $\mathrm{H}$, Dong $\mathrm{H}$, et al. Motherto-child transmission of hepatitis $B$ virus: evolution of hepatocellular carcinoma-related viral mutations in the post-immunization era. J Clin Virol. 2014; 61:47-54.

https://doi.org/10.1016/j.jcv.2014.06.010

PMID:24973814

43. Altschul SF, Gish W, Miller W, Myers EW, Lipman DJ. Basic local alignment search tool. J Mol Biol. 1990; 215:403-10.

https://doi.org/10.1016/S0022-2836(05)80360-2

PMID:2231712

44. Kumar S, Stecher G, Li M, Knyaz C, Tamura K. MEGA $\mathrm{X}$ : Molecular Evolutionary Genetics Analysis across Computing Platforms. Mol Biol Evol. 2018; 35: 1547-49.

https://doi.org/10.1093/molbev/msy096

PMID:29722887
45. Iasonos A, Schrag D, Raj GV, Panageas KS. How to build and interpret a nomogram for cancer prognosis. J Clin Oncol. 2008; 26:1364-70.

https://doi.org/10.1200/JCO.2007.12.9791

PMID:18323559

46. Robin X, Turck N, Hainard A, Tiberti N, Lisacek F, Sanchez JC, Müller M. pROC: an open-source package for $\mathrm{R}$ and $\mathrm{S}+$ to analyze and compare ROC curves. BMC Bioinformatics. 2011; 12:77.

https://doi.org/10.1186/1471-2105-12-77 PMID:21414208

47. Grant CE, Bailey TL, Noble WS. FIMO: scanning for occurrences of a given motif. Bioinformatics. 2011; 27:1017-18.

https://doi.org/10.1093/bioinformatics/btr064 PMID:21330290 


\section{SUPPLEMENTARY MATERIALS}

\section{Supplementary Figures}

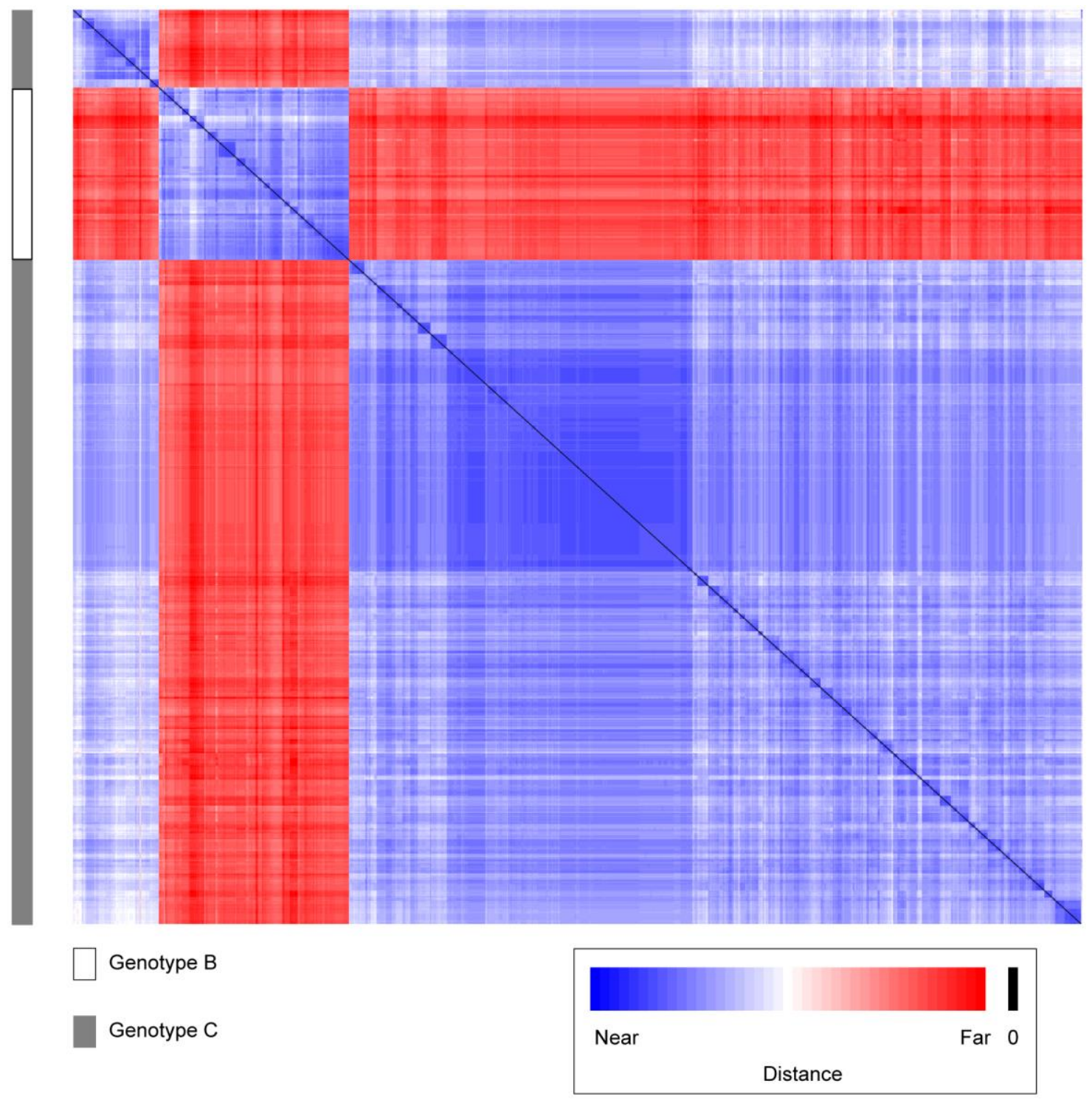

Supplementary Figure 1. Heat map of pairwise distances of the clones from the serum samples. Every row or column represents a clone. The grids on the diagonal line represent the distances between a clone and itself, which are all 0 (marked by black). 


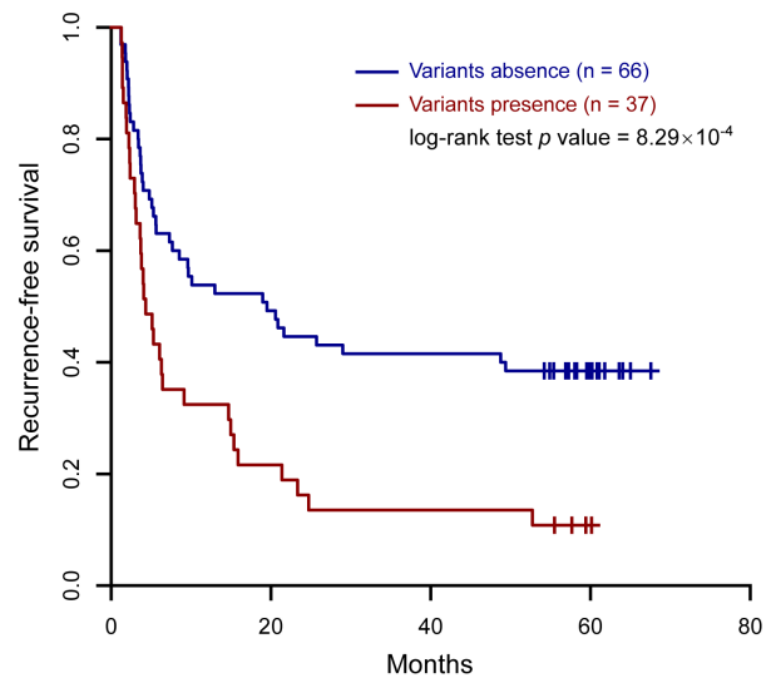

Supplementary Figure 2. Combined variants predicted unfavorable recurrence-free survival. G40C and C147T were combined because of their high frequency of concurrence. Kaplan-Meier curve was plotted to visualize the prognosis difference.
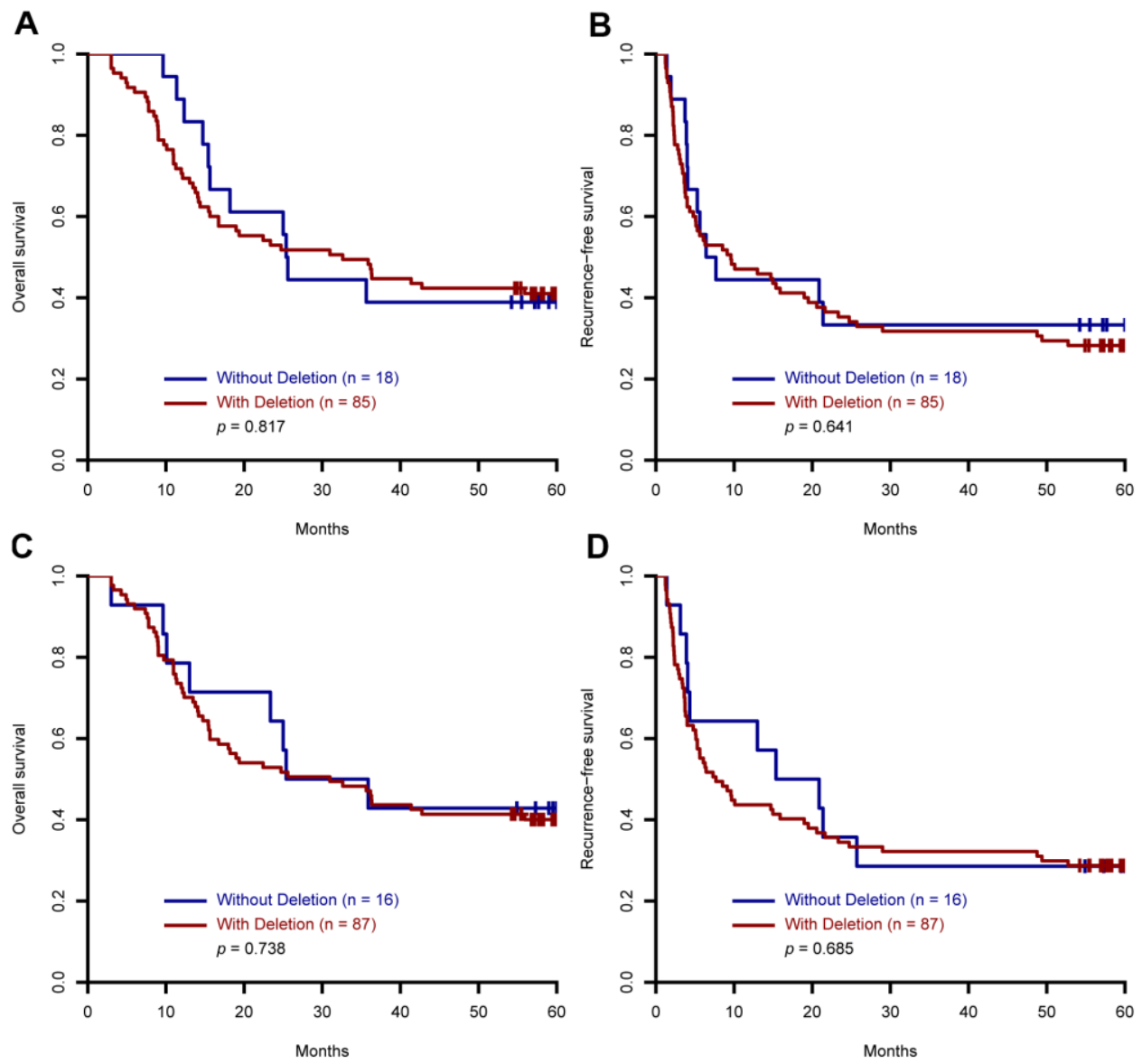

Supplementary Figure 3. The prognostic value of the preS2-deletion mutations in the HCC patients from our cohort. (A) the serum samples, overall survival; (B) the serum samples, recurrence-free survival; (C) tumoral samples, overall survival; (D) tumoral samples, recurrence-free survival. 


\section{Supplementary Tables}

Please browse Full Text version to see the data of Supplementary Table 6.

Supplementary Table 1. Liver cancer-specific and prognosis-related gene sets.

\begin{tabular}{lc}
\hline Gene set & Pubmed ID \\
\hline Overall survival-related gene sets & \\
LEE_LIVER_CANCER_SURVIVAL_DN & 15349906 \\
LEE_LIVER_CANCER_SURVIVAL_UP & 15349906 \\
HOSHIDA_LIVER_CANCER_SURVIVAL_UP & 18701503 \\
HOSHIDA_LIVER_CANCER_SURVIVAL_DN & 18701503 \\
KIM_LIVER_CANCER_POOR_SURVIVAL_UP & 21320499 \\
KIM_LIVER_CANCER_POOR_SURVIVAL_DN & 21320499 \\
Recurrence-free survival-related gene sets & \\
IIZUKA_LIVER_CANCER_EARLY_RECURRENCE & 12648972 \\
HOSHIDA_LIVER_CANCER_LATE_RECURRENCE_UP & 18923165 \\
HOSHIDA_LIVER_CANCER_LATE_RECURRENCE_DN & 18923165 \\
WOO_LIVER_CANCER_RECURRENCE_UP & 18381945 \\
WOO_LIVER_CANCER_RECURRENCE_DN & 18381945 \\
KUROKAWA_LIVER_CANCER_EARLY_RECURRENCE_UP & 15288478 \\
KUROKAWA_LIVER_CANCER_EARLY_RECURRENCE_DN & 15288478 \\
\hline
\end{tabular}

Supplementary Table 2. Association between HBV variants frequencies and HCC recurrence-related gene sets.

\begin{tabular}{|c|c|c|c|c|}
\hline Variant & Gene set & $\begin{array}{c}\text { Pearson } \\
\text { correlation }\end{array}$ & $P$ value & FDR \\
\hline G40C & KUROKAWA_LIVER_CANCER_EARLY_RECURRENCE_UP & 0.29 & $2.11 \mathrm{E}-03$ & $2.54 \mathrm{E}-02$ \\
\hline G45C & KUROKAWA_LIVER_CANCER_EARLY_RECURRENCE_UP & 0.28 & 2.19E-03 & $2.63 \mathrm{E}-02$ \\
\hline $\mathrm{A} 85 \mathrm{G}$ & KUROKAWA_LIVER_CANCER_EARLY_RECURRENCE_UP & 0.27 & $2.21 \mathrm{E}-03$ & $2.65 \mathrm{E}-02$ \\
\hline A87G & KUROKAWA_LIVER_CANCER_EARLY_RECURRENCE_UP & 0.25 & 5.39E-03 & $6.47 \mathrm{E}-02$ \\
\hline T93C & KUROKAWA_LIVER_CANCER_EARLY_RECURRENCE_UP & 0.26 & $4.51 \mathrm{E}-03$ & $5.42 \mathrm{E}-02$ \\
\hline $\mathrm{C} 105 \mathrm{~T}$ & KUROKAWA_LIVER_CANCER_EARLY_RECURRENCE_UP & 0.26 & $3.91 \mathrm{E}-03$ & 4.69E-02 \\
\hline C110G & KUROKAWA_LIVER_CANCER_EARLY_RECURRENCE_UP & 0.25 & $6.11 \mathrm{E}-03$ & 7.33E-02 \\
\hline C127A & KUROKAWA_LIVER_CANCER_EARLY_RECURRENCE_UP & 0.26 & $3.69 \mathrm{E}-03$ & 4.43E-02 \\
\hline G132A & KUROKAWA_LIVER_CANCER_EARLY_RECURRENCE_UP & 0.28 & $1.82 \mathrm{E}-03$ & $2.19 \mathrm{E}-02$ \\
\hline $\mathrm{C} 147 \mathrm{~T}$ & KUROKAWA_LIVER_CANCER_EARLY_RECURRENCE_UP & 0.24 & $6.87 \mathrm{E}-03$ & $8.24 \mathrm{E}-02$ \\
\hline
\end{tabular}

Abbreviations: FDR, false discovery rate. 
Supplementary Table 3. Recurrence-related HBV variants validated by sanger sequencing in the tumors.

\begin{tabular}{lccc}
\hline Variant & Hazard ratio & 95\% confidence interval & P value \\
\hline G40C & 1.78 & $1.04-3.05$ & $4.49 \mathrm{E}-02$ \\
G45C & 1.63 & $0.95-2.79$ & $8.63 \mathrm{E}-02$ \\
A85G & 1.74 & $1.02-2.98$ & $5.30 \mathrm{E}-02$ \\
A87G & 1.72 & $1.01-2.91$ & $5.45 \mathrm{E}-02$ \\
T93C & 1.54 & $0.90-2.62$ & $1.29 \mathrm{E}-01$ \\
C96A & 1.74 & $1.02-2.98$ & $5.30 \mathrm{E}-02$ \\
C99A & 1.60 & $0.95-2.71$ & $9.00 \mathrm{E}-02$ \\
C105T & 0.94 & $0.55-1.61$ & $8.31 \mathrm{E}-01$ \\
C110G & 1.69 & $0.98-2.92$ & $7.23 \mathrm{E}-02$ \\
C127A & 1.43 & $0.86-2.40$ & $1.83 \mathrm{E}-01$ \\
G132A & 1.59 & $0.95-2.67$ & $8.94 \mathrm{E}-02$ \\
C147T & 1.74 & $1.03-2.95$ & $4.84 \mathrm{E}-02$ \\
\hline
\end{tabular}


Supplementary Table 4. Cox regression analysis for the factors significantly affected the recurrence of postoperative HCC patients.

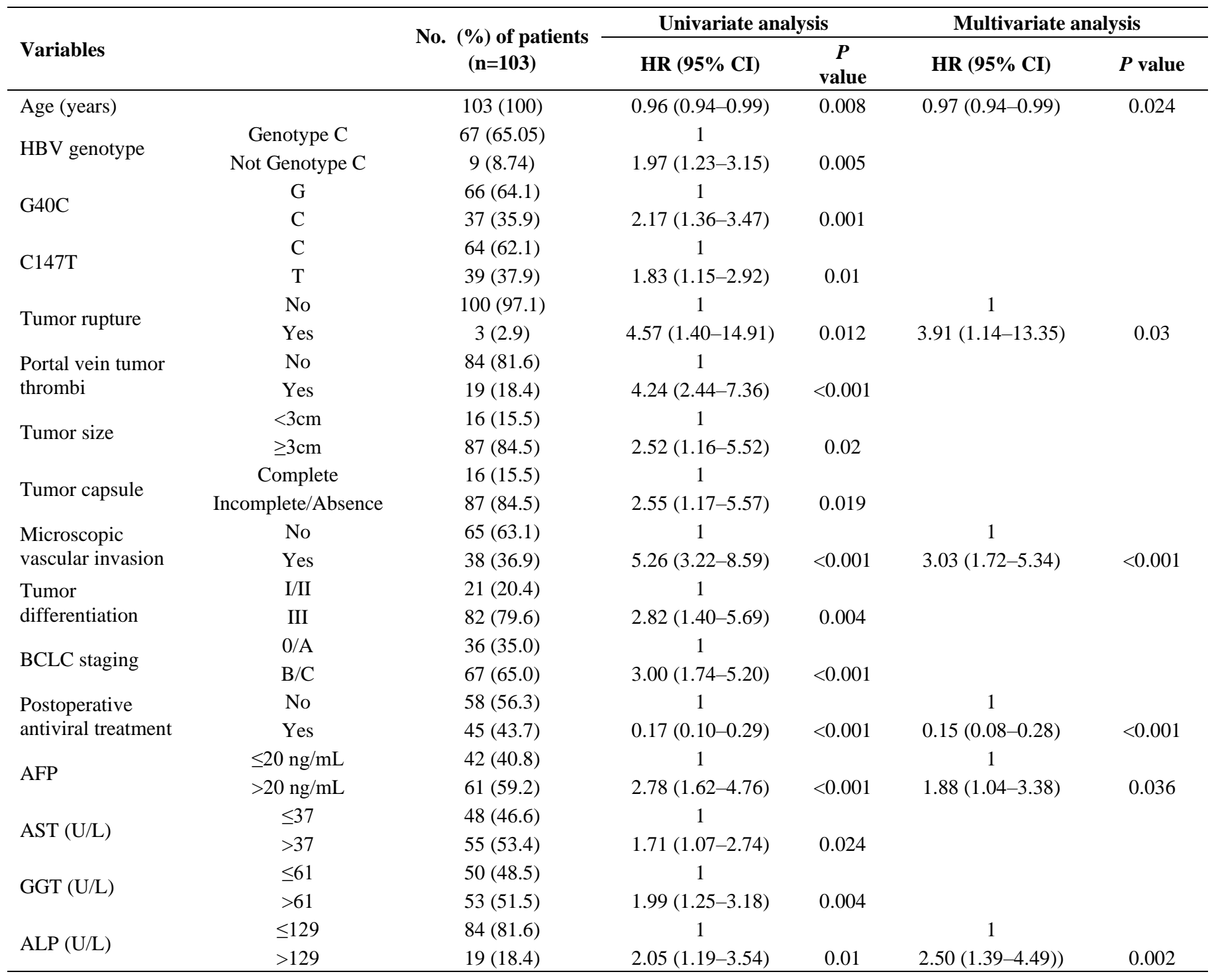

Abbreviations: $\mathrm{Cl}$, confidence interval; HBV, hepatitis B virus; $\mathrm{HCC}$, hepatocellular carcinoma; HR, hazard ratio; AST, aspartate aminotransferase; GGT, $\gamma$-glutamyltranspeptidase; AFP, $\alpha$-fetoprotein; ALP, alkaline phosphatase. 
Supplementary Table 5. Cox regression analysis for the factors significantly affected the recurrence of postoperative HCC patients stratified by antiviral treatment.

\begin{tabular}{|c|c|c|c|}
\hline \multirow{2}{*}{ Variables } & & \multicolumn{2}{|c|}{ Multivariate analysis } \\
\hline & & HR $(95 \%$ CI $)$ & $P$ value \\
\hline \multicolumn{4}{|c|}{ With postoperative antiviral treatment $(n=45)$} \\
\hline \multirow{2}{*}{ G40C } & G & 1 & \\
\hline & $\mathrm{C}$ & $3.89(1.39-10.87)$ & 0.01 \\
\hline \multirow{2}{*}{ BCLC staging } & 0/A & 1 & \\
\hline & $\mathrm{B} / \mathrm{C}$ & $4.63(1.53-14.02)$ & 0.007 \\
\hline \multirow{2}{*}{ AFP $(\mathrm{ng} / \mathrm{mL})$} & $\leq 20$ & 1 & \\
\hline & $>20$ & $5.88(1.88-18.39)$ & 0.002 \\
\hline \multicolumn{4}{|c|}{ Without postoperative antiviral treatment $(n=58)$} \\
\hline Age (years) & & $0.96(0.93-0.99)$ & 0.024 \\
\hline \multirow{2}{*}{ Tumor rupture } & No & 1 & \\
\hline & Yes & $5.07(1.43-17.99)$ & 0.012 \\
\hline \multirow{2}{*}{ Microscopic vascular invasion } & No & 1 & \\
\hline & Yes & $4.00(2.07-7.72)$ & $<0.001$ \\
\hline \multirow{2}{*}{$\mathrm{ALP}(\mathrm{U} / \mathrm{L})$} & $\leq 129$ & 1 & \\
\hline & $>129$ & $2.85(1.43-5.65)$ & 0.003 \\
\hline
\end{tabular}

Abbreviations: $\mathrm{Cl}$, confidence interval; $\mathrm{HCC}$, hepatocellular carcinoma; HR, hazard ratio; AFP, $\alpha$-fetoprotein; ALP, alkaline phosphatase.

Supplementary Table 6. Differentially expressed genes in the tumors with high/low frequencies of two HBV variants.

Supplementary Table 7. Transcription factor binding sites predicted in the region of preS2.

\begin{tabular}{lccccccc}
\hline Motif ID & Transcription factor & Start & Stop & Strand & Score & $\boldsymbol{P}$ value & FDR \\
\hline MA0484.1 & HNF4G & 138 & 152 & - & 8.38 & $2.25 \mathrm{e}-4$ & 0.06 \\
MA0505.1 & Nr5a2 & 29 & 43 & + & 4.90 & $4.93 \mathrm{e}-4$ & 0.07 \\
MA0505.1 & Nr5a2 & 40 & 54 & - & 3.34 & $7.89 \mathrm{e}-4$ & 0.07 \\
MA0505.1 & Nr5a2 & 35 & 49 & + & 3.21 & $8.21 \mathrm{e}-4$ & 0.07 \\
MA1101.1 & BACH2 & 30 & 43 & - & 6.69 & $3.69 \mathrm{e}-4$ & 0.10 \\
MA0114.3 & Hnf4a & 136 & 151 & - & -4.58 & $4.23 \mathrm{e}-4$ & 0.11 \\
MA0501.1 & MAF::NFE2 & 28 & 42 & - & 3.16 & $4.18 \mathrm{e}-4$ & 0.12 \\
MA1147.1 & NR4A2::RXRA & 35 & 49 & - & 5.77 & $5.69 \mathrm{e}-4$ & 0.15 \\
MA0150.2 & Nfe212 & 32 & 46 & - & 3.61 & $7.08 \mathrm{e}-4$ & 0.20 \\
MA0728.1 & Nr2f6(var.2) & 27 & 41 & + & -18.34 & $8.13 \mathrm{e}-4$ & 0.23 \\
MA0138.2 & REST & 135 & 155 & + & -3.04 & $9.58 \mathrm{e}-4$ & 0.23 \\
\hline
\end{tabular}

Abbreviation: FDR, false discovery rate. 
Supplementary Table 8. Gene sets enriched in the tumors with high/low frequencies of two HBV variants.

\begin{tabular}{|c|c|c|c|c|c|}
\hline Gene set & Size & ES & NES & P value & FWER \\
\hline \multicolumn{6}{|l|}{ Gene sets enriched in the tumors with low frequencies of two HBV variants } \\
\hline CHIANG_LIVER_CANCER_SUBCLASS_PROLIFERATION_DN & 178 & -0.52 & -2.73 & $<1 \mathrm{E}-3$ & $<1 \mathrm{E}-3$ \\
\hline CHIANG_LIVER_CANCER_SUBCLASS_CTNNB1_UP & 170 & -0.51 & -2.66 & $<1 \mathrm{E}-3$ & $<1 \mathrm{E}-3$ \\
\hline CAIRO_HEPATOBLASTOMA_CLASSES_DN & 213 & -0.44 & -2.35 & $<1 \mathrm{E}-3$ & 0.003 \\
\hline LEE_LIVER_CANCER_SURVIVAL_UP & 177 & -0.44 & -2.32 & $<1 \mathrm{E}-3$ & 0.005 \\
\hline FARMER_BREAST_CANCER_CLUSTER_1 & 47 & -0.52 & -2.15 & $<1 \mathrm{E}-3$ & 0.051 \\
\hline \multicolumn{6}{|l|}{ Gene sets enriched in the tumors with high frequencies of two HBV variants } \\
\hline NIKOLSKY_BREAST_CANCER_8Q23_Q24_AMPLICON & 145 & 0.62 & 2.86 & $<1 \mathrm{E}-3$ & $<1 \mathrm{E}-3$ \\
\hline CHIANG_LIVER_CANCER_SUBCLASS_PROLIFERATION_UP & 174 & 0.56 & 2.62 & $<1 \mathrm{E}-3$ & $<1 \mathrm{E}-3$ \\
\hline SOTIRIOU_BREAST_CANCER_GRADE_1_VS_3_UP & 152 & 0.52 & 2.41 & $<1 \mathrm{E}-3$ & $<1 \mathrm{E}-3$ \\
\hline BOYAULT_LIVER_CANCER_SUBCLASS_G3_UP & 190 & 0.51 & 2.41 & $<1 \mathrm{E}-3$ & 0.001 \\
\hline LEE_LIVER_CANCER_SURVIVAL_DN & 174 & 0.51 & 2.39 & $<1 \mathrm{E}-3$ & 0.001 \\
\hline KAMMINGA_EZH2_TARGETS & 40 & 0.65 & 2.39 & $<1 \mathrm{E}-3$ & 0.001 \\
\hline NIKOLSKY_BREAST_CANCER_8Q12_Q22_AMPLICON & 122 & 0.54 & 2.38 & $<1 \mathrm{E}-3$ & 0.001 \\
\hline NIKOLSKY_BREAST_CANCER_17Q11_Q21_AMPLICON & 105 & 0.54 & 2.32 & $<1 \mathrm{E}-3$ & 0.001 \\
\hline KOBAYASHI_EGFR_SIGNALING_24HR_DN & 251 & 0.47 & 2.32 & $<1 \mathrm{E}-3$ & 0.001 \\
\hline BURTON_ADIPOGENESIS_3 & 93 & 0.54 & 2.32 & $<1 \mathrm{E}-3$ & 0.001 \\
\hline MITSIADES_RESPONSE_TO_APLIDIN_DN & 247 & 0.47 & 2.28 & $<1 \mathrm{E}-3$ & 0.001 \\
\hline ROSTY_CERVICAL_CANCER_PROLIFERATION_CLUSTER & 140 & 0.50 & 2.27 & $<1 \mathrm{E}-3$ & 0.001 \\
\hline SHEDDEN_LUNG_CANCER_POOR_SURVIVAL_A6 & 445 & 0.44 & 2.25 & $<1 \mathrm{E}-3$ & 0.002 \\
\hline WONG_EMBRYONIC_STEM_CELL_CORE & 332 & 0.45 & 2.24 & $<1 \mathrm{E}-3$ & 0.002 \\
\hline BORCZUK_MALIGNANT_MESOTHELIOMA_UP & 308 & 0.44 & 2.20 & $<1 \mathrm{E}-3$ & 0.006 \\
\hline AGUIRRE_PANCREATIC_CANCER_COPY_NUMBER_UP & 294 & 0.45 & 2.19 & $<1 \mathrm{E}-3$ & 0.007 \\
\hline VILLANUEVA_LIVER_CANCER_KRT19_UP & 167 & 0.46 & 2.16 & $<1 \mathrm{E}-3$ & 0.01 \\
\hline CHIN_BREAST_CANCER_COPY_NUMBER_UP & 23 & 0.68 & 2.16 & $<1 \mathrm{E}-3$ & 0.01 \\
\hline CHIANG_LIVER_CANCER_SUBCLASS_UNANNOTATED_DN & 192 & 0.46 & 2.15 & $<1 \mathrm{E}-3$ & 0.011 \\
\hline RHODES_CANCER_META_SIGNATURE & 65 & 0.54 & 2.15 & $<1 \mathrm{E}-3$ & 0.011 \\
\hline ABRAMSON_INTERACT_WITH_AIRE & 43 & 0.57 & 2.14 & $<1 \mathrm{E}-3$ & 0.014 \\
\hline DAVICIONI_MOLECULAR_ARMS_VS_ERMS_DN & 174 & 0.45 & 2.11 & $<1 \mathrm{E}-3$ & 0.022 \\
\hline LI_WILMS_TUMOR_VS_FETAL_KIDNEY_1_DN & 164 & 0.46 & 2.10 & $<1 \mathrm{E}-3$ & 0.023 \\
\hline LE_EGR2_TARGETS_UP & 107 & 0.48 & 2.09 & $<1 \mathrm{E}-3$ & 0.029 \\
\hline REN_BOUND_BY_E2F & 61 & 0.52 & 2.07 & $<1 \mathrm{E}-3$ & 0.042 \\
\hline WOO_LIVER_CANCER_RECURRENCE_UP & 103 & 0.48 & 2.07 & $<1 \mathrm{E}-3$ & 0.043 \\
\hline PAL_PRMT5_TARGETS_UP & 200 & 0.43 & 2.07 & $<1 \mathrm{E}-3$ & 0.043 \\
\hline WAMUNYOKOLI_OVARIAN_CANCER_GRADES_1_2_UP & 139 & 0.46 & 2.07 & $<1 \mathrm{E}-3$ & 0.044 \\
\hline HEIDENBLAD_AMPLIFIED_IN_PANCREATIC_CANCER & 55 & 0.53 & 2.07 & $<1 \mathrm{E}-3$ & 0.047 \\
\hline BIDUS_METASTASIS_UP & 210 & 0.43 & 2.06 & $<1 \mathrm{E}-3$ & 0.051 \\
\hline JECHLINGER_EPITHELIAL_TO_MESENCHYMAL_TRANSITION_DN & 56 & 0.53 & 2.06 & $<1 \mathrm{E}-3$ & 0.052 \\
\hline WHITEFORD_PEDIATRIC_CANCER_MARKERS & 113 & 0.47 & 2.06 & $<1 \mathrm{E}-3$ & 0.052 \\
\hline JIANG_AGING_CEREBRAL_CORTEX_DN & 45 & 0.55 & 2.06 & $1.55 \mathrm{E}-03$ & 0.054 \\
\hline MEINHOLD_OVARIAN_CANCER_LOW_GRADE_DN & 19 & 0.67 & 2.05 & $<1 \mathrm{E}-3$ & 0.058 \\
\hline TURASHVILI_BREAST_LOBULAR_CARCINOMA_VS_DUCTAL_NORMAL_UP & 66 & 0.51 & 2.05 & $<1 \mathrm{E}-3$ & 0.059 \\
\hline GRAHAM_NORMAL_QUIESCENT_VS_NORMAL_DIVIDING_DN & 87 & 0.49 & 2.05 & $<1 \mathrm{E}-3$ & 0.061 \\
\hline NIKOLSKY_BREAST_CANCER_17Q21_Q25_AMPLICON & 298 & 0.41 & 2.04 & $<1 \mathrm{E}-3$ & 0.069 \\
\hline YAO_TEMPORAL_RESPONSE_TO_PROGESTERONE_CLUSTER_14 & 143 & 0.45 & 2.04 & $<1 \mathrm{E}-3$ & 0.072 \\
\hline MARKEY_RB1_ACUTE_LOF_UP & 229 & 0.42 & 2.04 & $<1 \mathrm{E}-3$ & 0.074 \\
\hline DING_LUNG_CANCER_EXPRESSION_BY_COPY_NUMBER & 100 & 0.47 & 2.03 & $<1 \mathrm{E}-3$ & 0.076 \\
\hline CROONQUIST_IL6_DEPRIVATION_DN & 95 & 0.47 & 2.03 & $<1 \mathrm{E}-3$ & 0.076 \\
\hline HOSHIDA_LIVER_CANCER_SUBCLASS_S2 & 114 & 0.45 & 2.03 & $<1 \mathrm{E}-3$ & 0.082 \\
\hline RHODES_UNDIFFERENTIATED_CANCER & 69 & 0.50 & 2.03 & $<1 \mathrm{E}-3$ & 0.085 \\
\hline VECCHI_GASTRIC_CANCER_ADVANCED_VS_EARLY_UP & 169 & 0.43 & 2.02 & $<1 \mathrm{E}-3$ & 0.088 \\
\hline BLUM_RESPONSE_TO_SALIRASIB_DN & 336 & 0.40 & 2.02 & $<1 \mathrm{E}-3$ & 0.091 \\
\hline FUJII_YBX1_TARGETS_DN & 194 & 0.43 & 2.02 & $<1 \mathrm{E}-3$ & 0.091 \\
\hline MARKEY_RB1_CHRONIC_LOF_UP & 107 & 0.47 & 2.02 & $<1 \mathrm{E}-3$ & 0.097 \\
\hline
\end{tabular}

Abbreviation: ES, enrichment score; NES, normalized ES; FWER, familywise-error rate. 